\title{
Gendered Leadership Expectations in Sport: Constructing Differences in Coaches
}

\author{
Vicki D. Schull and Lisa A. Kihl \\ University of Minnesota
}

\begin{abstract}
The purpose of this study is to examine the gendered nature of sport leadership by analyzing female college athletes' perceptions of leadership associated with sport coaching. Semi-structured interviews were conducted with 23 female college athletes participating in NCAA Division I team sports to understand their perceptions of leadership associated with coaching and to examine the gendered nature of their leadership constructions. Findings indicated two gendered leadership attributes were associated with coaching (i.e., human capital and empathy) in the context of women's college sport. While both men and women were cited as ideal leaders based on their human capital and ability to express empathy, these leadership attributes were evaluated and applied differently to male and female coaches. The gendered nature of human capital and empathy contributed to the further privileging of men and certain forms of dominant masculinities over women and forms of femininities within notions of sport leadership and coaching. This study contributes to the gender and sport literature and offers practical implications focused on individual and interpersonal strategies.
\end{abstract}

Keywords: coaching, college sport, empathy, gender, social processes, sport capital

A masculine ethic is ubiquitous to leadership and notions of what it means to be a good leader across many organizational contexts (Eagly, 2007; Fine, 2009). Traditional leadership conceptions espouse stereotypical masculine qualities such as powerful, direct/assertive, agency, and command and control over subordinates (Fine, 2009). Fletcher (2004) also contends that everyday narratives around leadership remain embedded in images of heroic individualism, authority, and aggressiveness - traits and behaviors socially constructed as masculine and more often linked to men. Masculine leadership ideologies are particularly persistent in male-dominated fields and occupations, and when women are able to break into maledominated fields, they are often marginalized and feel the effects of gendered stereotypes due in part to how the leadership construct is based on masculine traits and ideologies. (Fine, 2009).

The social institution of sport features a long and gendered history where traditional notions of masculinity (e.g., physicality, power, dominance) are valued and reproduced (Anderson, 2009), and where dominant masculine ideals and characteristics associated with leadership are perhaps more deeply embedded and persistent than any other arena (Hovden, 2000, 2010). The masculine context of sport teamed with dominant masculine leadership ideologies often results in gendered logic and beliefs that men are naturally better sport leaders and coaches, and recent research found the position of head coach and associated roles more closely match stereotypical masculine traits and characteristics compared to characteristics associated with ideal assistant coaches (Madsen, Burton \& Clark, 2017). It is widely reported that women continue to be marginalized and underrepresented in sport leadership positions, including coaching and administration (e.g., Acosta \& Carpenter, 2016; LaVoi, 2013), due in large part to the dominant masculine culture of sport (Walker \& Satore-Baldwin, 2013).

Schull and Kihl are with the School of Kinesiology, University of Minnesota, Minneapolis, MN. Schull (schu1850@umn.edu) is corresponding author.
For example, female college athletes have expressed preferences for male coaches based on the gendered logic that men possess greater sport knowledge, enforce discipline, and garner respect through authoritarian leadership practices (Drago, Hennighausen, Rogers, Vescio, \& Stauffer, 2005; Frey, Czech, Kent, \& Johnson, 2006; Madsen, 2016; Schull, 2016). Male coaches are also often perceived to display greater professionalism because they are more likely to keep their personal lives private (Drago et al., 2005), and college athletes valued masculine agentic traits more in head coaches than in assistant coaches (Madsen et al., 2017). While sport leadership traits and characteristics associated with coaching align well with certain forms of masculinities (e.g., authority, assertiveness, heroic individualism), leadership traits and characteristics that are socially ascribed as "feminine" such as nurturing, relational, and emotional (Eagly, 2007; Fletcher, 2004) are less valued in sport leadership (Hovden, 2010) and coaching (Madsen et al., 2017; Schull, 2016). Female coaches are often expected to provide emotional labor, support, and to develop relationships with their athletes, and yet when they fulfill these expectations, they subsequently may be disrespected as disciplinarians or denigrated for being 'too emotional' (Drago et al., 2005; Frey et al., 2006; Schull, 2016). The tensions between the emotional supportive qualities expected of female leaders and the authoritarian, masculine qualities expected of sport leaders and coaches often places female coaches in a gender conundrum or double bind (Eagly, 2007) that can be difficult to navigate (Drago et al., 2005; Grapendorf \& Burton, 2017).

Much of the scholarship examining the lack of women in sport leadership and coaching focuses on current female sport leaders and the organizations and systems in which they work (for reviews see Burton, 2015; Burton \& Leberman, 2017). Female college athletes represent a large pool of women who are potential candidates for future sport leadership positions, and their perceptions of leadership in sport can provide another perspective on women's stagnation within sport leadership and coaching. Madsen (2016), 
for example, found that gendered social roles were influential to the decisions of female college athletes to pursue more feminine careers outside of sports. Female college athletes may come to understand leadership in the context of sport as a gendered social process given that their sport experiences are dominated both by male leaders and masculine values associated with sport leadership. Social processes are gendered based on the degree to which they are defined, described, and evaluated in terms of masculine and feminine, male and female, and/or men and women, which often leads to the privileging of men and dominant masculine traits over women and traditional feminine traits (Acker, 1992; Britton, 2003; Ely \& Meyerson, 2000). In sport, gendered assumptions often underpin beliefs that men are more qualified and competent sport leaders and coaches. Thus, we argue that exploring female college athletes' constructions of leadership in the context of college sport and the gendered assumptions, beliefs, and ideologies associated with coach leadership may provide nuanced understandings of women' underrepresentation in sport leadership and coaching.

The purpose of this study was to examine the gendered nature of leadership in sport by analyzing female college athletes' perceptions of leadership associated with coaching. The following research questions guided this study: 1) How do female athletes perceive leadership associated with coaching? and 2) If and in what ways are female college athletes' perceptions of leadership attributes associated with coaching gendered? While our study assumes a link between coaching and leadership, it is important to note that leadership is just one of many qualities related to coaching. In order to pursue the purpose, we first provide an overview of the theoretical frameworks of the study highlighting gendered social processes (Acker, 1992; Britton, 2003; Ely \& Meyerson, 2000). Next, we describe the research design. Our findings and discussion are presented in the following section, and our final section provides practical implications and conclusions.

\section{Theoretical Framework}

A three-part conceptualization of gendered social processes (Britton, 2003) serves as the theoretical framework and analytical lens to assess the gendered nature of leadership perceptions. Drawing from and refining Acker's (1992) seminal work on gendered organizational processes, Britton (2003) identifies three levels of gendered processes: 1) structure and patterns of work (e.g., formal and informal practices and policies); 2) culture (e.g., images, narratives, ideologies); and 3) agency (e.g., gender appropriate behaviors, interactions, and identities) (Britton, 2003; Britton \& Logan, 2008). It is important to note that while the levels can be separated for analysis, they often play out in interconnected ways (Acker, 1992; Britton, 2003). This three-part framework thus allows us to not only examine and understand how leadership may be gendered at each level, but also to understand connections between levels while identifying gendered logic underpinning sport leadership perceptions.

\section{Structure and Patterns of Work}

The concept of work is traditionally organized around a separation between the public sphere of work and the private sphere of home and domestic responsibilities (Britton, 2003; Ely \& Meyerson, 2000). The ideal worker is able to separate between the two spheres and focus on work tasks free from distractions in the private sphere. Such work arrangements favor men and men's lives, who historically assume fewer domestic responsibilities (Ely \& Meyerson,
2000). It is this organization of work and the formal and informal policies and practices associated with different types of work that can operate to segregate, exclude, or construct gender hierarchies in groups and organizations (Acker, 1992; Britton \& Logan, 2008). For example, positions in sport, including the coaching profession, and the work they entail are very demanding and require long and irregular working hours as well as travel. The demands placed on coaches are frequently constraining to women and mothers who take on greater family responsibilities, and the lack of work-life balance is, at the very least, a challenge for women (Bruening \& Dixon, 2008; Leberman \& Palmer, 2008), and has been cited as reason why some women leave the coaching profession (Drago et al., 2005; Kamphoff, 2010).

Other organizational processes and practices (e.g., hiring, job qualifications, leadership selection) may implicitly favor men and masculine ideals while marginalizing others including women. For example, Hovden (2000) found that leadership selection processes in Norwegian sport organizations consisted of heroic corporate leadership and "heavyweight" qualifications that included sport experience, extensive political and business contacts, and competence in financial management and strategic planning. The qualifications, while seemingly gender-neutral, were more consistent "with a middle-aged male manager most likely interested in high-performance sport" (Hovden, p. 27). In a similar examination, Schull, Kihl, and Shaw (2013) found that gendered political processes in the search for an athletic director resulted in gendered candidate criteria inherently linked to male candidates.

Patterns of work and employment practices (e.g., job responsibilities and qualification) are influential to developing human capital, which Ployhart and Moliterno (2011) conceptualize as knowledge, skills, experiences, and other abilities and characteristics related to individuals. Cunningham and Sagas (2002) examined human capital of Division I basketball coaches using four measures: educational background, playing experience, coaching experiences, and coaching tenure. Their results suggested little differences between male and female coaches in terms of education; however, women demonstrated greater college playing experiences, longer playing careers, and received more athletic honors and awards (Cunningham \& Sagas). While the male coaches in the study had less playing experiences, they held more coaching roles compared to women and benefited more from the effects of human capital. Why this gendered effect of human capital exists is less understood.

\section{Culture}

Gendered narratives and other symbolic expressions sustain dominant cultural images of social institutions, organizations, and occupations by creating and reproducing gendered ideologies (Britton, 2003; Britton \& Logan, 2008). These ideologies or forms of consciousness often go unrecognized and unquestioned and become part of the tapestry of social life (Britton \& Logan, 2008; Ely \& Meyerson, 2000). Gendered narratives and assumptions are very influential to conceptions of leadership — such as the notion that men are more likely to display assertive and transactional leadership styles, while women are more likely to display relational leadership styles (Eagly, 2007; Fine, 2009; Fletcher, 2004).

Sport is embedded in a culture of hyper masculinity (Anderson, 2009) and researchers have examined gendered ideologies including masculine superiority and dominance in coaching (Drago et al., 2005; Fielding-Lloyd \& Mean, 2008; Messner \& Bozada-Deas, 2009) as well as gendered narratives and images 
associated with sport leadership (Hovden, 2000, 2010; Knoppers \& Anthonissen, 2008; Schull et al., 2013; Shaw, 2006; Sibson, 2010). Hovden (2010) focused on the construction of female leadership and associated images and found that female sport leaders were portrayed in terms of their deviations and deficits from traditionally masculine leadership discourses. The narratives framing leadership images included beliefs female leaders were less inclined to make tough decisions, were less competitive and ambitious, and lacked competence and experience (Hovden, 2010). Female sport leadership images collectively established masculine ideals as the norm while characterizing feminine/female behavior as the difference, and more importantly_as a deficiency within the context of sport.

\section{Agency}

Agency refers to gender appropriate behaviors, personas, and identities impacting constructions of leadership in two ways (Britton, 2003). First, individuals may internalize gender appropriate behaviors congruent with the organizational or social context as they interpret their leadership experiences (Britton, 2003). This involves crafting one's identity to correspond with what is perceived to be gender appropriate for the specific context. Second, individuals are often judged by what behaviors are perceived to be gender appropriate within a specific context (Britton, 2003). Given the body of research around gender differences in leadership, which is often prescriptive in nature-that is, men are expected to be assertive leaders, while women are expected to employ collaborative and relational leadership practices - this gendered social process category is relevant to our examination. Agency and gender appropriate behaviors associated with leadership also implicate the "double-bind" that often confronts women in leadership positions. (Eagly, 2007, p. 4). For example, women are expected to display agentic masculine traits because they are leaders while also being expected to display more collaborative and communal feminine traits because they are women. However, both sets of expectations cause problems for female leaders because they are judged negatively when they express traditionally masculine traits (e.g., authoritarian, rational, hard) and are undervalued when they express traditionally feminine traits (e.g., nurturing, too emotional, or soft) (Eagly, 2007; Fletcher, 2004). In a sport context, Shaw and Hoeber (2003) found overt masculinities were vital to success in senior management positions in sport organizations. However, women who expressed masculinities too openly were also penalized and excluded from senior management because of these behaviors.

Hurst, Leberman, and Edwards (2017) recently found that women in a variety of occupational settings have higher relational expectations of their female managers compared to their male managers in terms of emotional understanding and support. They also found that relationships between female employee and female manager were strained when the relational expectations were not met. Hurst et al.'s study highlights how gendered expectations around management and leadership play out in a variety of organizational settings. In a sport setting, Knoppers and Anthonissen (2008) found that male sport managers used gendered discourses to present their work in ways that created heroic masculine forms of leadership. Participant discourses of instrumentality (e.g., "toughness", "availability", and "impression management") reinforced a gendered culture that tended to exclude outsiders, including women and minorities, from sport management positions. Participants also relied on "discourses of relationality" (Knoppers \& Anthonissen, 2008, p. 97) with implicit paterno-authoritarian overtones to help craft their identities as heroic individual leaders. For example, many men claimed to engage in informal relational leadership practices they believed were people oriented. However, the paterno-authoritative overtones (e.g., protective nature of authority) allowed the participants to establish agency - that is they positioned themselves as in control or in charge of subordinates (Knoppers \& Anthonissen, 2008).

Leadership and gender are both inherently social products influenced by socio-cultural factors. Leadership is a social process, constructed and embedded in a context where history, assumptions, and meanings matter (Osborn, Hunt, \& Jauch, 2002), while gender is positioned as a set of social relations where ideals and assumptions of what it means to be a man or a woman, masculine or feminine are constructed, expressed and reproduced through complex social processes (Britton \& Logan, 2008; Ely \& Meyerson, 2000). This framework helped to uncover deeply rooted ideologies and beliefs about leadership embedded in a specific sport culture and illuminated how gendered constructions and expectations can operate to keep women locked out of sport leadership positions.

\section{Methods}

\section{Research Design}

This study was part of a larger project that examined how female college athletes socially construct leadership in a sport context widely associated with men and privileged forms of masculinities. Furthermore, we sought to examine how participants' sport experiences informed their perceptions of leadership within a specific context (i.e., National Collegiate Athletic Association [NCAA] Division I) to answer Elliot and Stead's (2008) call for increased attention on women's experiences of leadership within specific socio-historic contexts. Two core categories of leadership emerged in the larger study (i.e., coach and peer leadership), and here we focus and draw on data related to coach leadership. An interpretive qualitative design underpinned by a constructivist paradigm was employed to capture the complex and dynamic aspects of social processes including leadership and gender. The strategy of inquiry featured a narrative approach and utilized semi-structured qualitative interviews to solicit participants' first-hand accounts (Rubin \& Rubin, 2005) of leadership and meanings of gender in sport. Examples of questions featured in the interview guide include: Based on your experiences in sport, what does leadership mean to you?; What experiences and/or who from your sport experiences have influenced your beliefs about leadership in sport?; Of your previous coaches, who would consider an ideal leader? What makes him/her an ideal leader?; Can you describe a specific example where this coach displayed ideal leadership?; and How important do you think gender is to leadership in sport? This design was effective in valuing the participants' varied subjective experiences and recognizing that, as researchers, our own experiences play a role in how we interpret participants' experiences and perceptions.

\section{Participants}

Participants were recruited in two ways using convenience sampling. Initially, the first author solicited help from head coaches of women's intercollegiate athletic teams, athletic administrators, and athletic staff members (i.e., athletic academic counselors). 
These individuals agreed to email an introductory letter outlining the research to potential participants, who were instructed to contact the first author in order to participate in the research. The second and more effective recruitment strategy consisted of identifying potential participants via team websites and using public institutional email directories to subsequently contact potential participants via email and invite them to participate in the study. The criteria for inclusion were female athletes who 1) were either currently participating at the NCAA Division I level or who recently (i.e., within three to six months) completed their athletic eligibility; 2) participated in team sports; and 3) who had two or more years of intercollegiate playing experience. These criteria were used because it provided rich information cases (Patton, 2002), that is, individuals who had a range of previous leadership experiences with sport coaches and participation in team sports and thus would provide insights into the complexity of views in the construction of leadership and relevancy of gender within NCAA Division I college sport. Twenty-three female athletes representing six different teams from a large NCAA Division I university in the mid-west participated in the study. Athlete participants included five soccer $(n=5)$, five rowers $(n=5)$, four basketball $(n=4)$, four ice hockey $(n=4)$, three volleyball $(n=3)$ and two softball $(n=2)$ (see Table 1$)$. The participants included eight fourth-year $(n=8)$, 10 third-year $(n=10)$, and five second-year $(n=5)$ players. All participants were assigned pseudonyms.

\section{Data Generation and Analysis}

A semi-structured interview guide was used that provided flexibility to pursue clarifying information and details about the participants' perceptions and experiences of leadership and meanings of gender. The interview guide contained three types of questions. First, background and demographic questions (e.g., sports played, years of experience, and history with male and female coaches) helped position participants within the study (Patton, 2002). Second, opinion and value questions were helpful in understanding participants' cognitive and interpretive processes (Patton, 2002). For example, participants were asked how important gender was in coaching and if their expectations differed for male and female leaders. Third, experience and behavior questions (Patton, 2002) were posed to generate rich descriptions of the participants' subjective experiences with leadership in sport coaching. For example, participants were asked to reflect on their experiences with both male and female coaches, and how these experiences informed their leadership perceptions. As part of this inquiry, participants were also asked to identify an ideal leader among their past and/or current coaches and to describe specific situations where their coach(es) demonstrated ideal leadership. Data was collected over a year-long period (2013-2014). Participant interviews continued until responses became repetitive and broad enough in scope to ensure saturation and sufficiency was reached

Table 1 Participants

\begin{tabular}{|c|c|c|c|c|c|}
\hline $\begin{array}{l}\text { Current College } \\
\text { Sport }\end{array}$ & Pseudonym & $\begin{array}{l}\text { Year of } \\
\text { Eligibility }\end{array}$ & $\begin{array}{l}\text { Gender of Current } \\
\text { Head Coach }\end{array}$ & $\begin{array}{l}\text { Gender of Current } \\
\text { Assistant Coaches }\end{array}$ & $\begin{array}{l}\text { Gender of Previous } \\
\text { Coaches Discussed: }\end{array}$ \\
\hline Basketball & Amy & Junior & Female & Male, Male, Female & Male (HS Track \& Field) \\
\hline Basketball & Carley & Junior & Female & Male, Male, Female & Male (HS BB) \\
\hline Basketball & Mindy & Senior* & Female & Male, Male, Female & NA \\
\hline Basketball & Stephanie & Junior & Female & Male, Male, Female & NA \\
\hline Ice Hockey & Angie & Junior & Male & Male, Male, Female & Female (HS Soccer) \\
\hline Ice Hockey & Julie & Senior & Male & Male, Male, Female & Female \\
\hline Ice Hockey & Kay & Junior & Male & Male, Male, Female & Male (HS Hockey) \\
\hline Ice Hockey & Lindsey & Senior & Male & Male, Male, Female & Male (HS Golf \& Hockey) \\
\hline Rowing & Beth & Senior* & Female & Female, Female, Male & Male (HS BB) \\
\hline Rowing & Dana & Sophomore & Female & Female, Female, Male & Male (VB) \\
\hline Rowing & Erin & Senior* & Female & Female, Female, Male & Male (HS BB) \\
\hline Rowing & Jen & Sophomore & Female & Female, Female, Male & Male (HS BB) \\
\hline Rowing & Jess & Sophomore & Female & Female, Female, Male & Male (HS BB) \\
\hline Soccer & Allie & Junior & Female & Female, Female, Male & Male (HS Soccer) \\
\hline Soccer & Emily & Junior & Female & Female, Female, Male & Male (HS Soccer) \\
\hline Soccer & Katie & Sophomore & Female & Female, Female, Male & Male (HS Soccer) \\
\hline Soccer & Jill & Senior* & Female & Female, Female, Male & $\begin{array}{l}\text { Male (HS BB) } \\
\text { Male (Travel Soccer) } \\
\text { Female (ODP Soccer) }\end{array}$ \\
\hline Soccer & Nicole & Senior & Female & Female, Female, Male & Female (HS Gymnastics) \\
\hline Softball & $\mathrm{Liz}$ & Senior* & Female & Female, Female, Female & $\begin{array}{l}\text { Female (HS SB) } \\
\text { Male (Travel SB) }\end{array}$ \\
\hline Softball & Shelly & Junior & Female & Female, Female, Female & Female (HS SB) \\
\hline Volleyball & Andrea & Junior & Male & Male, Female, Male & Male (Travel VB) \\
\hline Volleyball & Kelly & Sophomore & Male & Male, Female, Male & Female (HS VB) \\
\hline Volleyball & Sarah & Junior* & Male & Male, Female, Male & Male (HS VB) \\
\hline
\end{tabular}

* Served as Team Captain. 
(Denzin \& Lincoln, 2005; Rubin \& Rubin, 2005). Interviews were digitally recorded, transcribed verbatim, and ranged from 3560 minutes in length.

All data were then prepared and downloaded into the qualitative software program HyperRESEARCH (Hesse-Beber, Dupis, \& Kinder, 1991) for data organization and management. To gain familiarity with the data, transcripts were carefully read by the researchers and initial codes and themes were inductively identified based on the research questions. Next open coding was performed and resulted in the development of categories defined by their respective properties and dimensions. Axial coding involved pinpointing relationships between categories to further develop concepts and themes (Corbin \& Strauss, 2008). For example, the concept of empathy was an emergent feature to participants' perceptions of coach leadership and axial coding was instrumental in not only connecting the concept of empathy to cultural images of leadership, but also to reveal the gendered expectations of empathy. Thus, axial coding resulted in the initial integration of categories and properties with the various themes organized around leadership and gender.

Second, thematic analysis was performed to identify common patterns of meaning and perceptions of leadership associated with sport coaching and gender across the participants' narratives (Boyatzis, 1998; Braun \& Clarke, 2006). While the categories, properties, and dimensions of leadership were inductively derived from the data through the coding process, gendered leadership themes were developed by integrating the work of several gender and leadership scholars (e.g., Britton, 2003; Eagly, 2007; Hovden, 2010). This abductive analysis process resulted in the identification of two gendered leadership constructs associated with coaches.

\section{Methodological Integrity}

Strategies used to establish the integrity of the methods and demonstrate the overall trustworthiness of the study included adhering to standards of credibility, dependability and confirmability (Denzin \& Lincoln, 2005). To address credibility member checks and peer debriefing techniques were used (Johnson \& Christensen, 2004; Lincoln, 1985). Member checks were carried out throughout the data collection and analysis stages that helped to ensure that the reconstructions of the participants' multiple realities were adequately represented in the research (Lincoln, 1985). For example, during interviews probing and follow up questions along with paraphrasing of responses provided by participants were used to ensure accuracy of their statements. To confirm accuracy of the interview transcripts, research participants were also invited to member check these documents. Peer debriefing meetings between the two researchers occurred eight times throughout the data generation and data analysis process. During these meetings, we discussed various aspects of the research including the emerging categories and themes, interpretations of the data, and critically analyzed methodological issues to address preconceived biases (Lincoln, 1985).

To establish dependability in this research, thick description of data was sought through in-depth interviews and an external reviewer with no connection to the study examined the research process (Lincoln, 1985). The external reviewer examined the interview guide, the transcripts, and the findings. This step enhanced the integrity of the study by verifying that the interview guide asked questions that addressed the purpose of the research and ensured that the analysis representations of the data were accurate. Last, confirmability was achieved by performing an external audit (i.e., product audit). An audit trail of relevant records (i.e., raw data; data analysis notes, summaries, and themes; process notes; and reflective notes) was developed and maintained (Lincoln, 1985). The external reviewer examined the findings, interpretations, and conclusions to ensure that they were supported by the data (Lincoln, 1985).

\section{Results and Discussion}

Two gendered leadership attributes associated with coaching emerged from participants' narratives and leadership perceptions including human capital (i.e., sport playing experience, coaching experience and sport knowledge) and empathy. Applying a gendered social process analysis, we found these leadership attributes to be gendered in two inter-related ways. First, human capital and empathy were evaluated using different standards for male coaches compared to the standards used to evaluate female coaches. Second, human capital and empathy carried with them different sets of expectations associated with and assigned to male and female coaches. These leadership attributes contributed to the construction of gendered leadership associated with coaching in the sport context.

\section{Human Capital}

Female athletes often referred to their coaches' previous sport experiences as a relevant factor to coaches' leadership abilities. Such experiences including playing experience, coaching experience, and general sport knowledge, represent categories of human capital in sport settings, and previous research suggests human capital has differential effects for male and female coaches (Cunningham \& Sagas, 2002). A gendered social process approach can provide deeper understanding into how gendered differences in human capital are constructed and play out in sport.

She Played and He Just Knows. Human capital was gendered based on the different standards of sport experiences and qualifications used to evaluate male and female coaches. Female coaches were often expected to possess human capital in the form of previous playing experience in order to be considered an ideal sport leader. For example:

She [current assistant coach] used to play and she's a four-time Olympian-a phenomenal player. (Angie, hockey)

She [current assistant coach] was a great player . . . she went to two Final Fours, so she has that [i.e., playing experience] behind her backing her up. (Sarah, volleyball)

[Current assistant coach] is kind of younger and I think tries to be a leader by connecting with our team. . . . Just a couple of years ago, [she] was in our shoes. So, helping us that way by her experiences. (Amy, basketball)

Being able to believe [in] and have that trust factor . . . . [Current head coach] definitely has the skills, she was an AllAmerican [player] from [University A] and our assistant coach was an All-America from [University B] . . . . We definitely have a talented staff. (Liz, softball)

Not only did female coaches need previous playing experience to be considered an ideal leader, but the playing experience highlighted was consistently at an elite level (e.g., NCAA Division I or National level), which provided credibility to female assistant coaches and legitimized their leadership roles. 
Human capital for male coaches, on the other hand, was described in terms of their coaching experience and sport knowledge. Stephanie (basketball), "He's [current assistant] coached for so many years and he just knows a lot of stuff". For Lindsey (hockey), sport knowledge resulted in respect and trust for her high school [golf and hockey] coach:

He knew a lot about both golf and hockey, and so we could talk about both games for hours-out on the course or at the rink . . .. I knew he was knowledgeable and I could respect that .... If he told us to do it this way, we could because we knew he knew what he was talking about.

Knowledge of sport was seemingly inherent and unquestioned in male coaches as Carley (basketball) stated, "You really respected what he [HS head coach] was saying, and he just knew what he was talking about". Erin (rower) discussed her current male assistant coach in similar terms: "He just knew what he was talking about and he just demanded respect, and you gave it to him because you had no reason not to."

While human capital in male coaches was characterized in part by inherent knowledge of the sport, it was also importantly characterized by the near absence of sport playing experience. Only one participant, Kelly referred to a male coach's playing experience as an important sport leadership qualification:

He [current assistant] used to be very good, he was on [elite national team], so he knows a lot about team chemistry. He also knows a lot about coaching [and is] a leader in the coaching world. (Kelly, volleyball)

Rather than identifying their ability to play the sport, more often, participants cited either coaching experience as human capital in male coaches, which Kelly also referred to in her above comment, or their innate knowledge of the sport-both of which seem unchallenged. Therefore, human capital represented a type of privileged masculinity (Connell, 2005). That is, knowledge of the sport is often inherent and assumed in male coaches, and justified through a gendered logic where men "just know" a lot about sport, as if it were simply a natural consequence of being a man.

Discussion. Playing experience was cited as a leadership attribute associated with their female coaches-one that afforded women credibility because playing experience provided legitimacy and "backed up" their coaching qualifications. In the context of women's college sport, standards of human capital play out as gendered due to the perceptions that female coaches need reinforcement to be considered competent coaches, and this "back up" reads as not just playing experience, but playing experience at an elite level (e.g., Olympic, NCAA Final Four Championship, NCAA Division I).

Conversely, playing experience was fundamentally a nonissue to leadership qualifications and perceptions associated with male coaches. Role congruity suggests that male coaches are perceived to be more aligned with head coach and associated roles based on stereotypical notions of masculinity (i.e., assertive and agentic) (Madsen et al., 2017), which provides one explanation why male coaches do not seem to require playing experience. Moreover, the near absence of playing experience as a form of human capital for male coaches in this research is an important finding because it reveals a type of privileged masculinity specific to the context of women's college sport. Cunningham, Sagas, and Ashley (2001) suggest that sport playing experience is one important factor for men coaching men's intercollegiate athletic teams. However, here we see that men who do not possess college playing experience are still able to enjoy privilege in coaching positions within women's college sport. Put another way, some men who fall short of the standards of dominant masculinity in men's college sport are welcomed in women's college sport where they are revered as sport leaders in part due to their inherent and unchallenged sport knowledge. A gendered logic underpinned the participant quotes comprising the 'he just knows' theme. This distinction is important for two reasons.

First, Britton (2003) suggests men in feminized jobs and organizations (e.g., nursing and teaching), are often welcomed and praised for their leadership abilities. The context here is critical because while sport and the sport culture are indisputably male dominated and masculinized, the participants in women's college sport are exclusively women. The female participants (i.e., athletes) in this research often welcomed male coaches, valued their presence as leaders, and respected their contributions to sport leadership in the context of women's college sport. We therefore extend Britton's findings to the decidedly masculine context of sport, yet a context exclusively featuring female participants.

Second, masculinity in sport was not linked to athletic talent or status as an athlete, which shows that gender is not staticmasculinity in sport does not simply equate to athleticism. This is noteworthy because it demonstrates the multiple ways gender can play out in sport and answers Ashcraft's (2009) call for examinations of the complexity of gender in various contexts. However, this contribution is overshadowed by the problematic mechanism through which male coaches in this study were still naturally linked to expertise in sport and perceived to be ideal leaders, due in part to their assumed and often unquestioned sport knowledge and congruence with masculine head coach characteristics (Madsen et al., 2017). On the other hand, female coaches in this study, did not experience this leadership privilege around sport knowledge. Fielding-Lloyd and Mean (2008) similarly found that masculinity equated to expertise in English soccer coach education, and we extend their findings to U.S college sport in the current study.

The connections between male coaches, expertise, and sport knowledge reflects the deeply embedded nature of masculinity in the sport culture and demonstrates how taken for granted assumptions valuing men and forms of masculinity are difficult to disrupt in the sport context. While Walker and Satore-Baldwin (2013) found that a hypermasculine and gender exclusive culture prevented female coaches from entering the realm of men's sport (i.e., men's basketball), male coaches in our study did not face the same constraints when entering women's sport. Male coaches who lack human capital in the form of elite playing experiences are still often perceived to be (more) knowledgeable about sport and are seen as (more) credible and capable sport leaders based on stereotypical notions of masculinity associated with head coaching roles (Madsen et al., 2017). Adding yet another layer of gendered difference-that is, the notion that female coaches need playing experience to "back them up" and to legitimize their presence as sport leaders and coaches-make the gendered assumptions in sport even still more difficult to disrupt. Perceptions around the assistant coaches' roles are, to a lesser degree, linked to stereotypical masculine beliefs (Madsen et al., 2017) which also helps to explain why participants in this study more often identified their female assistant coaches as ideal leaders rather than their female head coaches. 


\section{Empathy}

Empathy emerged as a valued leadership attribute associated with coaching. Empathy is defined as the ability to comprehend and feel another's emotions, and to understand and appreciate their perspective (Goleman, Boyatzis, \& McKee, 2002; Salovey \& Mayer, 1990). Scholars recognize empathy as an important leadership skill—one that fosters the development of trusting relationships (Garner, 2009) and creates resonance with followers through shared experiences and emotions (Goleman et al., 2002; Kellett, Humphrey, \& Sleeth, 2006). Female athlete participants viewed empathy in similar terms and valued their coaches' abilities to comprehend their feelings, to understand their perspectives and experiences as female athletes, and to relate to them. The relevancy to the purpose of this research was that coaches' abilities to express empathy were connected to positive leadership perceptions, and yet expectations still varied between male and female coaches and played out differently for female head and assistant coaches.

Rewards, Penalties, and Free Passes. Participants often cited female assistant coaches as ideal leaders in sport for their expressions of empathy represented in the following quotes:

[Current assistant coach] actually played, so she knows and understands how we're feeling more .... . She's very understanding of how our bodies feel or why a drill's not working. (Allie, soccer)

[High school SB coach] was younger too, and she could relate to us girls in a way that she would know-she would know how to talk to us on and off the field. (Liz, softball)

[Current assistant coach] is young, and she's really cool about things. She's been through the program here before as a player, so she knows how it is. (Stephanie, basketball)

I would say [current assistant coach] is very natural in her position. She can be hard on us when she has to, and she understands us, so she can take us in a room to talk to us when she thinks she has to. (Lindsey, hockey).

The ability of female assistant coaches to express empathy was a valued aspect of sport leadership and was related to human capital. The participant quotations clearly revealed the perception that female (mostly assistant) coaches were able to comprehend the feelings of the participants due to their past sport playing experiences, which facilitated one dimension of empathy and understanding. It is also noteworthy that female assistant coaches mentioned in the above quotes also served under head male coaches, and/or were often younger and closer in age to the participants.

Female assistant coaches who exemplify empathy were often cited as ideal leaders and praised for their ability to relate, signaling positive perceptions associated with empathy, leadership and female assistant coaches. Empathy was also gendered in that participants expected female coaches would understand them simply based on their identities as women, which naturalized empathy as a gender specific leadership behavior. Female coaches who did not embody empathy and understanding faced greater scrutiny from female athlete participants, and this scrutiny more often impacted female head coaches:

For some reason, girls are going to take [getting yelled at] more personally from a female [head] coach. I see that tendency ... . maybe it's because you feel like a female coach understands how women are, so you think that the message they're trying to get across should be delivered differently, [because] they understand how you're probably going to take it. (Mindy, basketball)

I've had male [coaches], and I would just let stuff roll off my back-I would listen for the message behind whatever he was saying .... [But] with a woman [head coach], I just feel personally attacked if she screams at me. (Jill, soccer)

I think what some athletes want from a woman [head coach] is to understand that emotional part, where they think guys won't, but then again, I think if they're making that emotional part come to the field .... . For me-you leave it off the field. (Shelly, softball)

On the other hand, participants less often cited empathy as a relevant leadership attribute for male coaches or like Shelly indicated above, they just do not think male coaches can understand some of the experiences of female athletes. The discrepancy was explained through a gendered belief that not only naturalized men's lack of empathy and relational skills, but more importantly, excused it:

I guess you just don't think a male coach knows [how you feel], so they're just doing whatever just to yell at you ... and you just don't care. (Mindy, basketball)

From my past experiences, [male coaches] either can relate well to you or not so well [laughs] when usually, womenthey relate more to you because they understand what's going on, and they've obviously been through a lot of the [same] experiences being a woman, whereas guys, depending on their situation, may not understand as well. (Carley, basketball)

Interestingly, some participants perceived their male coaches' inability to understand their experiences was actually a positive dimension to their leadership.

I think it's good we have both male and female coaches .... Our male coaches are really good at focusing on the game and practice, and all that girly gossipy crap, [male coaches] think that doesn't matter. Whereas us, as a team and even [assistant female coach], might think it does matter and it plays a role into how we play and work together, but then it's good to have coaches who don't get wrapped up in all that stuff, which is usually male coaches who don't understand all that, so it's good that [male coaches] just kind of throw that to the side. (Julie, hockey)

Also noteworthy was when male coaches were identified as empathetic leaders, which was less frequently, their empathy was attributed to experiences other than their sport playing experiences. Rather, the ability of male coaches to display empathy in leadership was attributed to roles and experiences as fathers in their personal lives. For example:

He [HS basketball coach] really knew how to relate to us, and I think when coaches have kids, they know, especially having girls [i.e., daughters] for a guy [coach] . . . and he was just easy to talk to. (Carley, basketball)

I don't know if it was because he [HS soccer coach] had two daughters, and he knew how to work with girls, but his chemistry with girls on the team was amazing. (Katie, soccer) 
[Current assistant coach] has three [daughters], and so I think he kind of takes that fatherly role as kind of [his] leadership role. (Amy, basketball)

He [HS basketball coach] was my best friend's dad ... . I could see how much she loved and respected him ... . He'd always take care of us ... he'd always have our backs. (Beth, rowing)

While both men and women can display empathetic qualities, empathy is often believed to be more natural for women to display (Fletcher, 2004). Therefore, male coaches who were empathetic and could understand the female athletes-often due to their experiences as fathers-were idealized as leaders. Female assistant coaches perceived to be ideal leaders were similarly commended for their empathy and ability to understand the participants. However, female head coaches who did not display empathy were perceived less favorably as leaders, and in a sense, penalized for not adhering to gendered expectations of empathy. The penalty was linked to the belief that empathy was an inherent expectation of all female coaches based on their statuses as women and former experiences as female athletes (i.e., "they should know").

Discussion. Participants' perceptions of empathy in sport leadership were based on coaches' experiences as female athletes, women, and fathers. Empathy was also a natural leadership expectation for female coaches to perform; however, female assistant coaches were more likely to fulfill these expectations and garner praise, while female head coaches often fell short of relational expectations associated with empathy and drew criticism. On the other hand, while the perception existed that male (both head and assistant) coaches could be empathic, they were not expected to be so. This distinction is important because female college athletes' perceptions and expectations for empathy were differentially valued among their male and female coaches and draws attention to the gendered feature of empathy related to leadership in sport. Gendered expectations of empathy also provide nuance to how the double-bind (Eagly, 2007) can play out differently for women in head coaching roles, compared to those women serving as assistant coaches.

Relational leadership practices such as the expression of empathy are socially constructed as feminine (Eagly, 2007; Fletcher, 2004) and on the surface, would suggest that women are amply suited for sport leadership roles given the participants in this study valued empathy as a leadership attribute among their female assistant coaches. However, Knoppers and Antonissen (2008) found that when male sport managers add feminized attributes such as relational skills to their leadership repertoires, the reliance on women to fulfill relational leadership roles is lessened while men are rewarded and idealized for their exceptional leadership skills and abilities to relate to subordinates. It is also important to note the paternalistic narratives associated with sport leadership, and the perceptions that personal experiences of fatherhood contribute positively to a man's ability to express empathy in leadership; however, the same privilege did not extend to female coaches who were mothers. Tierney (1996) urges us to examine "how leadership is defined, who gets involved, and by definition, who gets left out" (p. 376). Thus, the absence of motherhood narratives linked to sport leadership and empathy suggests that the experiences of mothers serving as coaches were not valued by the participants in this research. The single participant who referred to motherhood used it negatively when she said, "Let your kids [i.e., athletes] be kids and let them-you can't try to be their mom at the same time" (Andrea). This comment stands in stark contrast to the paternalistic narratives of male coaches who were commended for their ability to display fatherly traits related to leadership and goes some length to demonstrate the notion that motherhood is not perceived as a leadership advantage and does not benefit female coaches the same way that fatherhood advantages male coaches.

Gendered expectations related to empathy and female coaches in this study echoes Hurst et al.'s (2017) findings of relational expectations placed on female managers in a variety of occupational settings. More specifically, in Hurst et al.'s study, women held higher relational expectations for other women, and when those expectation were not met, female managers suffered strained relationships or other relational penalties. Our findings suggest female head coaches may be penalized if they do not display relational leadership specifically in terms of empathy and understanding based on their similar experiences as female athletes (i.e., they should understand). We therefore extend Hurst et al.'s findings, first, to the context of sport and second, by showing that women in different leadership roles are impacted by gendered expectations differently. While both head and assistant female coaches are expected to display empathy, head coaches more often face penalties for not adhering to gendered expectations. Women in head coaching positions face conflicting roles where they are expected to display empathy and relational leadership because they are women while they are simultaneously expected to be agentic "in charge" leaders because they are head coaches.

In contrast, male coaches who were not empathetic did not face similar penalties and were often given a free pass simply because, "they just don't know" the experiences of female athletes, highlighting gendered expectations for male coaches. The so-called free pass related to empathy plays out as a double-advantage in leadership for male coaches compared to Eagly's (2007) doublebind-male coaches can be empathetic and are valued for demonstrating relational leadership skills, while, at the same time, their agentic (i.e., non-relational) skills are aligned with traditional notions of masculinity and are thus equally rewarded. Our finding supports Madsen et al.'s (2017) work that male coaches are further advantaged compared to women when seeking coaching positions because they are able to express agentic and relations skills without penalties. Finally, while some female athletes often perceive empathy in inherently gendered terms (i.e., women should understand other women, men do not understand women), their accounts of fatherhood related to leadership help challenge stereotyped notions and binary gender beliefs. Instead, father figure leaders were empathetic and could understand female athletes-especially if father figure leaders had daughters of their own. Here again, we echo Madsen et al.'s work that an ideal coach is able to demonstrate both stereotypical masculine and feminine characteristics. Furthermore, research in sport psychology (e.g., Gledhill \& Harwood, 2014) suggests fathers are influential to their daughters' sport experiences, and, given the emergence of a father privilege associated with leadership, the role that fathers play in shaping female athletes' perceptions of sport leadership should be further explored.

It is also important to note the gendered emotional work assigned to female assistant coaches. While they are often praised and idealized for their ability to display empathy and relate to female athletes, this work is often still marginalized and devalued. For example, Julie indicated (in previous quote) the "girly, gossipy crap" does matter and "plays a role" for her teammates and female assistant coach, while the male coaches can "throw that to the side" and "focus on the game and practice" - that is, the important work of coaching. In addition, many of the female assistant coaches cited 
by participants (i.e., Allie, Stephanie, Lindsey) for their relational leadership abilities served as assistants to male coaches, which supports Drago et al.'s (2005) finding that female assistant coaches were expected to provide "emotional labor" to female athletes, especially when coaching staffs are led by men.

Limitations. This study is limited in the sample which included participants from one NCAA Division I athletic program based on convenience. The results of this study were thus reflective of the experience and perceptions of the 23 participants and do not necessarily reflect the experiences and beliefs of other female college athletes. More specifically, this study may be unique to Division I female athletes participating in team sports (e.g., basketball, volleyball, softball, soccer, hockey, rowing), and may not reflect other specific populations such as Division II and III athletes, individual sport athletes, or high school athletes. This study is therefore limited in its ability to generalize findings to other sport settings.

\section{Conclusions and Practical Implications}

The pertinent findings in this research call attention to the gendered nature of sport leadership attributes associated with coaching, including human capital and empathy. The differential evaluation of human capital led to the privileging of men and certain forms of masculinities (i.e., maleness as sport knowledge and expertise), while simultaneously adding yet another obstacle for female coaches to overcome in terms of sport leadership attributes and beliefs (i.e., elite playing experience as a prerequisite). Perceptions of empathy in sport leadership resulted in stereotypical gendered expectations for both men and women. Men, however, were provided with more latitude in their expressions of empathy and often given a free pass when they did not display empathy while women were often penalized for not demonstrating empathy.

This research represents a theoretical contribution to the gendered relations literature by highlighting how leadership is a gendered construction in the context of college sport. More specifically, we have pinpointed some ways in which the meanings of masculinity/male and femininity/female permeate beliefs and conceptions of sport leadership and serve to maintain a state of play in sport privileging men and certain forms of masculinities. By identifying and examining gendered leadership narratives, expectations, and attributes, we can begin to challenge and dismantle them, leading to improved gender equality in sport.

Our analysis also recognizes the complexity of gender in leadership constructions within the sport context. In order to advance the gender relations literature, Ashcraft (2009) cautioned against a gender binary approach and instead suggests that "relentless interrogation-along the lines of which women and which men?-is a promising start" (p. 321). In this study, we have identified specific men (i.e., men without playing experience, fathers) and specific women (i.e., women with elite playing experience, young assistant coaches) whose leadership was evaluated with an underlying gendered logic. Also noteworthy was the specific women who were missing from the participants' leadership constructions-mothers. While motherhood and coach leadership was not a focus of this research, the absence of mothers cited as ideal leaders should not be ignored and justifies further investigation.

Gendered social processes operate in subtle ways to maintain gender biases and inequality, and in many cases, go undetected.
This is especially true in sport as men's dominance and masculine ethos continue to permeate perceptions of sport leadership. Change at the level of social processes is difficult to achieve due in part to the insidious nature of gendered processes and in part because change involves an ideological shift and large-scale socio-cultural change. This research offers several areas of practical implications focused on individual and interpersonal strategies which represent the starting point for enacting change. First, coach education programs would benefit from incorporating discussions about the impact of gendered social processes in sport leadership by encouraging coaches (both men and women) to reflect on their role in combating gendered logic and biases in sport leadership and coaching. When gendered narratives and ideology in sport leadership are expressed, as they were in this research, male and female coaches are in the position to push back and challenge such beliefs. For example, if female athletes believe a coach should demonstrate empathy, how and why do they then excuse men who do not display this leadership trait? Similarly, how and why do they penalize women coaches who do not display empathy? Female athletes could also be questioned about how human capital is evaluated as a leadership qualification and whether they perceive their own playing experience as human capital for sport leadership. While small, such discussions may begin to dismantle gendered ideology and narratives in sport leadership and perhaps even provide encouragement to female athletes to pursue careers in sport leadership and coaching.

Second, administrators could use these findings to reflect on how gendered social processes may impact evaluations of coach effectiveness and qualifications. College athletic departments may solicit feedback from athletes in the form of annual program evaluations and exit interviews, so understanding the presence of gendered social processes within athletes' perceptions and how those processes impact male and female coaches differently is vital to interpreting athlete evaluations and feedback. The 2014 firing of University of Iowa head field hockey coach, Tracey Griesbaum serves as one example. Griesbaum was fired in large part due to athlete complaints citing alleged abusive coaching behaviors (Hartley, 2014). Yet, there was no punishment to members of the University of Iowa football coaching staff after a 2011 strenuous practice left 13 members of the football team hospitalized (Hartley, 2014). While abusive coaching behaviors should not be condoned, it seems clear that a double standard was in effect, and/or perhaps none of the football players complained about the strenuous practice, which can also be connected to gendered expectations in sport. That is, male athletes are supposed to "man up", to remain silent, and not lodge complaints against their coaches highlighting how gendered expectations can also be damaging to male athletes. Either way, gendered social processes are operating within athlete perceptions of their coaches and should be challenged and understood.

Finally, the finding that female athletes hold gendered assumptions related to sport leadership is important and appears to be influenced by the lack of women in sport leadership and coaching positions. The practical implication is that we need to increase the number of women in sport leadership. While this is not a novel concept, it needs to be repeated, and we must recognize the positive impact the presence of female role models can have on young female athletes, as Erin stated:

It's kind of cool to see a female in that leadership, you know, power position [head coach] . . . . It's just kind of cool to say, 'Oh, I could do that, maybe'. You know, it just kind of gives you a personal role model. 
Our efforts to increase women in sport leadership positions within women's sport must be obstinate, and the importance for some young female athletes to see themselves in the reflection of their coaches cannot be understated as it relates to this charge.

\section{References}

Acker, J. (1992). From sex roles to gendered institutions. Contemporary Sociology, 21(5), 565-569. doi:10.2307/2075528

Acosta, R.V., \& Carpenter, L.J. (2014). Women in intercollegiate sport: A longitudinal, national study thirty-five year update (1977-2014). Retrieved from http://www.acostacarpenter.org

Anderson, E.D. (2009). The maintenance of masculinity among the stakeholders of sport. Sport Management Review, 12, 3-14. doi:10.1016/j.smr.2008.09.003

Ashcraft, K.L. (2009). Gender and diversity: Other ways to make a difference. In M. Alvesson, T. Bridgman, \& H. Willmott (Eds.), The Oxford handbook of critical management studies (pp. 305-327). London, UK: Oxford University Press.

Boyatzis, R.E. (1998). Transforming qualitative information: Thematic analysis and code development. Thousand Oaks, CA: Sage.

Braun, V., \& Clarke, V. (2006). Using thematic analysis in psychology. Qualitative Research in Psychology, 3(2), 77-101. doi:10.1191/ 1478088706qp063oa

Britton, D.M. (2003). At work in the iron cage: The prison as gendered organization. New York, NY: New York University Press.

Britton, D.M., \& Logan, L. (2008). Gendered organizations: Progress and prospects. Sociology Compass, 2(1), 107-121. doi:10.1111/j.17519020.2007.00071.x

Bruening, J.E., \& Dixon, M.A. (2008). Situating work-family negotiations within a life course perspective: Insights into the gendered experiences of NCAA Division I head coaching mothers. Sex Roles, 58, 10-23. doi:10.1007/s11199-007-9350-x

Burton, L.J. (2015). Underrepresentation of women in sport leadership: A review of research. Sport Management Review, 18(2), 155-165. doi:10.1016/j.smr.2014.02.004

Burton, L.J., \& Leberman, S. (2017). An evaluation of current research in sport leadership: Multilevel perspective. In L.J. Burton \& S. Leberman (Eds.), Women in sport leadership: Research and practice for change (pp. 16-32). New York, UK: Routledge.

Connell, R. (2005). Masculinities (2nd ed.). Berkley, CA: University of California Press.

Corbin, J., \& Strauss, A. (2008). Basics of qualitative research: Techniques and procedures for developing grounded theory (3rd ed.). Thousand Oaks, CA: Sage.

Cunningham, G.B., \& Sagas, M. (2002). The differential effects of human capital for male and female Division I basketball coaches. Research Quarterly for Exercise and Sport, 73(4), 489-495. PubMed ID: 12495253 doi:10.1080/02701367.2002.10609051

Cunningham, G.B., Sagas, M., \& Ashley, F.B. (2001). Occupational commitment and intent to leave the coaching profession: Differences according to race. International Review for the Sociology of Sport, 36(2), 131-148. doi:10.1177/101269001036002001

Denzin, N.K., \& Lincoln, Y.S. (2005). Introduction: The discipline and practice of qualitative research. In N.K. Denzin \& Y.S. Lincoln (Eds.), Handbook of qualitative research (3rd ed., pp. 1-41). Thousand Oaks, CA: Sage.

Drago, R., Hennighausen, L., Rogers, J., Vescio, T., \& Stauffer, K.D. (2005). CAGE: The coaching and gender equity project. Final report for NCAA, NACWAA and The Pennsylvania State University. Retrieved from http://lser.la.psu.edu/workfam/CAGE.htm
Eagly, A.H. (2007). Female leadership advantage and disadvantage: Resolving the contradictions. Psychology of Women Quarterly, 31, 1-12. doi:10.1111/j.1471-6402.2007.00326.x

Elliot, C., \& Stead, V. (2008). Learning from leading women's experience: Towards a sociological understanding, Leadership, 4(2), 159-180. doi: $10.1177 / 1742715008089636$

Ely, R.J., \& Meyerson, D.E. (2000). Theories of gender in organizations: A new approach to organizational analysis and change. Research in Organizational Behavior, 22, 103-151. doi:10.1016/S01913085(00)22004-2

Fielding-Lloyd, B., \& Mean, L.J. (2008). Standards and separatism: The discursive construction of gender in English soccer coach education. Sex Roles, 58, 24-39. doi:10.1007/s11199-007-9334-x

Fine, M.G. (2009). Women leaders' discursive constructions of leadership. Women's Studies in Communication, 32(2), 181-202. PubMed ID: 30376687

Fletcher, J.K. (2004). The paradox of postheroic leadership: An essay on gender, power, and transformational change. The Leadership Quarterly, 15, 647-661. doi:10.1016/j.leaqua.2004.07.004

Frey, M., Czech, D.R., Kent, R.G., \& Johnson, M. (2006). An exploration of female athletes' experiences and perceptions of male and female coaches. The Sport Journal, 9(4). Retrieved from http:// thesportjournal.org/

Garner, H.C. (2009). Empathy: A true leader skill. Military Review, 89(6), 84.

Gledhill, A., \& Harwood, C. (2014). Developmental experiences of elite female youth soccer players. International Journal of Sport \& Exercise Psychology, 12(2), 150-165. doi:10.1080/1612197X. 2014.880259

Goleman, D., Boyatzis, R.E., \& McKee, A. (2002). The new leaders: Transforming the art of leadership into the science of results (p. 14). London, UK: Little, Brown.

Grapendorf, H., \& Burton, L.A. (2017). The impact of bias in sport leadership. In L.J. Burton \& S. Leberman (Eds.), Women in sport leadership: Research and practice for change (pp. 47-61). New York, NY: Routledge.

Hartley, P. (2014, August 11). Former Iowa coach Beglin criticizes Griesbaum firing in letter. Iowa City Press-Citizen. Retrieved from https://www.press-citizen.com/

Hesse-Biber, S., Dupuis, P., \& Kinder, T.S. (1991). HyperRESEARCH: A computer program for the analysis of qualitative data with an emphasis on hypothesis testing and multimedia analysis. Qualitative Sociology, 14(4), 289-306. doi:10.1007/BF00989642

Hovden, J. (2000). "Heavyweight" men and younger women? The gendering of selection processes in Norwegian sports organizations. Nordic Journal of Feminist and Gender Research, 8(1), 17-32. doi:10.1080/080387400408035

Hovden, J. (2010). Female top leaders-prisoners of gender? The gendering of leadership discourses in Norwegian sports organizations. International Journal of Sport Policy, 2(2), 189-203. doi:10.1080/ 19406940.2010.488065

Hurst, J., Leberman, S., \& Edwards, M. (2017). The relational expectations of women managing women. Gender in Management: An International Journal, 32(1), 19-33. doi:10.1108/GM-02-20160016

Johnson, B., \& Christensen, L. (2004). Educational research: Quantitative, qualitative, and mixed approaches (2nd ed.). Boston, MA: Pearson Education.

Kamphoff, C. (2010). Bargaining with patriarchy: Former female coaches' experiences and their decision to leave college coaching. Research Quarterly for Exercise and Sport, 81(3), 360-372. PubMed ID: 20949856 
Kellett, J.B., Humphrey, R.H., \& Sleeth, R.G. (2006). Empathy and the emergence of task and relations leaders. The Leadership Quarterly, 17(2), 146-162. doi:10.1016/j.leaqua.2005.12.003

Knoppers, A., \& Anthonissen, A. (2008). Gendered managerial discourses in sport organizations: Multiplicity and complexity. Sex Roles, 58, 93-103. doi:10.1007/s11199-007-9324-z

LaVoi, N.M. (2013). The decline of women coaches in collegiate athletics: A report on select NCAA Division-I FBS institutions, 2012-13. Minneapolis, MN: The Tucker Center for Research on Girls \& Women in Sport.

Leberman, S., \& Palmer, F. (2009). Motherhood, sport leadership, and domain theory: Experiences from New Zealand. Journal of Sport Management, 23(3), 305-334. doi:10.1123/jsm.23.3.305

Lincoln, Y.S. (1985). Naturalistic inquiry. Beverly Hills, CA: Sage.

Madsen, R.M. (2016). "Dads play basketball, moms go shopping!" Social role theory and the preference for male coaches. Journal of Contemporary Athletics, 10(4), 277-291.

Madsen, R.M., Burton, L.J., \& Clark, B.S. (2017). Gender role expectations and the prevalence of women as assistant coaches. Journal for the Study of Sports and Athletes in Education, 11:2, 125-142. doi:10. 1080/19357397.2017.1315994

Messner, M.A., \& Bozada-Deas, S. (2009). Separating the men from the moms: The making of adult gender segregation in youth sports. Gender \& Society, 23(1), 49-71. doi:10.1177/0891243208327363

Osborn, R.N., Hunt, J.G., \& Jauch, L.R. (2002). Toward a contextual theory of leadership. The Leadership Quarterly, 13, 797-837. doi:10. 1016/S1048-9843(02)00154-6

Patton, M.Q. (2002). Qualitative evaluation and research methods (3rd ed.). Newbury Park, CA: Sage.

Ployhart, R.E., \& Moliterno, T.P. (2011). 'Emergence of the human capital resource: A multilevel model'. Academy of Management Review, 36(1), 127-150. doi:10.5465/amr.2009.0318
Rubin, H.J., \& Rubin, I.S. (2005). Qualitative interviewing: The art of hearing data (2nd ed.). Thousand Oaks, CA: Sage.

Salovey, P., \& Mayer, J.D. (1990). Emotional intelligence. Imagination, cognition and personality, 9(3), 185-211. doi:10.2190/DUGG-P24E52WK-6CDG

Schull, V. (2016). Female athletes' conceptions of leadership: Coaching and gender implications. In N.M. LaVoi (Ed.), Women in sports coaching (pp. 126-138). New York, NY: Routledge.

Schull, V., Shaw, S., \& Kihl, L.A. (2013). "If a woman came in ... she would have been eaten up alive": Analyzing gendered political processes in the search for an athletic director. Gender \& Society, 27(1), 56-81. doi:10.1177/0891243212466289

Shaw, S. (2006). Scratching the back of "Mr. X": Analyzing gendered social processes in sport organizations. Journal of Sport Management, 20, 510-534. doi:10.1123/jsm.20.4.510

Shaw, S., \& Hoeber, L. (2003). "A strong man is direct and a direct woman is a bitch": Gendered discourses and their influence on employment roles in sport organizations. Journal of Sport Management, 17, 347-375. doi:10.1123/jsm.17.4.347

Sibson, R. (2010). "I was banging my head against a brick wall": Exclusionary power and the gendering of sport organizations. Journal of Sport Management, 24(4), 379-399. doi:10.1123/jsm. 24.4.379

Tierney, W.G. (1996). Leadership and postmodernism: On voice and the qualitative method. The Leadership Quarterly, 7(3), 371-383. doi:10. 1016/S1048-9843(96)90026-0

Walker, N.A., \& Sartore-Baldwin, M.L. (2013). Hegemonic masculinity and the institutionalized bias toward women in men's collegiate basketball: What do men think? Journal of Sport Management, 27(4), 303-315. doi:10.1123/jsm.27.4.303 